\title{
Prolonged manometric recordings of oesophagus and lower oesophageal sphincter in achalasia patients
}

\author{
M A van Herwaarden, M Samsom, A J P M Smout
}

\begin{abstract}
Background and aims-Conventional short term manometry is a valuable tool in the diagnosis of achalasia but the technique may fail to detect intermittent motor events. The aim of this study was to investigate the pattern of lower oesophageal sphincter (LOS) and oesophageal pressures during prolonged recording in patients with achalasia.
\end{abstract}

Methods-Eleven patients with idiopathic achalasia were studied. Prolonged combined oesophageal $\mathrm{pH}$ and manometric recordings of the pharynx, LOS, and stomach were performed using a $\mathrm{pH}$ glass electrode and a multiple lumen assembly incorporating a Dent sleeve connected to a portable water perfused manometric system.

Results-LOS pressure varied during the day. Postprandial LOS pressures were lower than those recorded preprandially (1.2 $v 1.8 \mathrm{kPa} ; \mathrm{p}=0.005)$ and basal LOS pressures were significantly higher during phase III of the migrating motor complex than during the subsequent phase I (3.3 $v$ $1.8 \mathrm{kPa} ; \mathrm{p}=0.028)$. Complete LOS relaxations were occasionally observed in seven patients $(0.48 / \mathrm{h})$. Complete LOS relaxations were longer in duration than incomplete LOS relaxations $(10.8 v 2.8 \mathrm{~s} ; \mathrm{p}=\mathbf{0 . 0 1})$ and $57 \%$ of complete relaxations fulfilled the criteria of a transient LOS relaxation (TLOSR). Complete LOS relaxations were associated with oesophageal pressure waves with higher amplitudes and longer durations. In addition, a higher proportion of these oesophageal pressure waves were spontaneous $(55.6 \% \quad v \quad 0 \%$; $p<0.02)$ and multipeaked $(72.7 \%$ v $0 \%)$. During prolonged manometry, high amplitude oesophageal pressure waves $(>10$ $\mathrm{kPa}$ ) were recorded in six patients and retrograde oesophageal pressure waves in four, phenomena which were not observed during short term manometry.

Conclusion-In contrast with short term stationary manometry, prolonged manometry in achalasia patients revealed the occurrence of complete LOS relaxations, TLOSRs, variations in LOS pressure associated with a meal or phase III, and high amplitude and retrograde oesophageal pressure waves.

(Gut 2001;49:813-821)

Keywords: achalasia; lower oesophageal sphincter; manometry; oesophagus
Achalasia is a rare primary neurogenic motility disorder of the oesophagus and lower oesophageal sphincter (LOS) with dysfunction of the inhibitory innervation as the most prominent feature. ${ }^{1}$ Neuropathological findings in the oesophagus and LOS of achalasia patients include degeneration and reduction of ganglion cells within the myenteric plexus, reduction of vasoactive intestinal polypeptide and nitric oxide nerve fibres in the myenteric plexus, and degenerative lesions of the vagal nerves and the dorsal motor nucleus of the vagal nerve. ${ }^{2-7}$ These neuronal abnormalities are associated with non-specific changes in oesophageal smooth muscle. ${ }^{8}$

Short term stationary manometric recording is the gold standard for the diagnosis of achalasia showing absence of peristalsis and incomplete or absent LOS relaxation in response to wet swallows. ${ }^{9}$ The simultaneous pressure waves that are seen in the oesophageal body of achalasia patients during conventional manometry usually have a low amplitude. ${ }^{10}$ Three studies describing the occurrence of complete LOS relaxations in some achalasia patients during short term manometry have cast some doubt on the validity of the traditional manometric criteria for achalasia. ${ }^{11-13}$ However, in two of these studies LOS pressure was not recorded using a sleeve sensor. ${ }^{11}{ }^{12}$ Therefore, it might be that these apparently complete LOS relaxations were an artefact caused by proximal movement of the LOS associated with swallowing, moving the orifice in and out of the LOS. In the third study, undertaken with a sleeve, complete LOS relaxations were defined as a relaxation of $>80 \%$ and therefore residual LOS pressures were between 0.24 and $0.6 \mathrm{kPa} .{ }^{13}$

Several short term manometric studies investigated the effects of gastrointestinal hormones on LOS pressures in achalasia. ${ }^{14-19}$ They showed that these hormones can affect the LOS of achalasia patients, albeit that the magnitude of the effect in achalasia patients is mostly different from that in healthy volunteers. To our knowledge, only one study has been published in which prolonged recording of LOS pressures in achalasia patients was carried out. In this overnight study, a rise in LOS pressure associated with phase III of the interdigestive migrating motor complex (MMC) was observed in two patients. ${ }^{20}$

Some prolonged manometric studies of the oesophageal body in achalasia patients have been performed. ${ }^{21-23}$ In contrast with short

Abbreviations used in this paper: LOS, lower oesophageal sphincter; TLOSR, transient LOS relaxation; MMC, migrating motor complex. 
Table 1 Patient characteristics and symptoms

\begin{tabular}{|c|c|c|c|c|c|c|c|c|c|c|c|c|c|c|c|}
\hline \multirow{2}{*}{$\begin{array}{l}\text { Patient } \\
\text { No }\end{array}$} & \multirow[b]{2}{*}{ Sex } & \multirow[b]{2}{*}{ Age (y) } & \multirow{2}{*}{$\begin{array}{l}\text { Age at onset } \\
\text { symptoms }(y)\end{array}$} & \multirow[b]{2}{*}{ Previous treatment } & \multirow{2}{*}{$\begin{array}{l}\text { Oesophageal } \\
\text { diameter }\end{array}$} & \multicolumn{2}{|c|}{$\begin{array}{l}\text { Dysphagia } \\
\text { for solids }\end{array}$} & \multicolumn{2}{|c|}{$\begin{array}{l}\text { Dysphagia } \\
\text { for liquids }\end{array}$} & \multicolumn{2}{|c|}{$\begin{array}{l}\text { Retrosternal } \\
\text { pain }\end{array}$} & \multicolumn{2}{|c|}{ Regurgitation } & \multicolumn{2}{|c|}{ Heartburn } \\
\hline & & & & & & $F$ & $S$ & $F$ & $S$ & $F$ & $S$ & $F$ & $S$ & $F$ & $S$ \\
\hline 1 & $\mathrm{~F}$ & 24 & 20 & $\mathrm{PD}(1 \times 3+2 \times 1)$ & 2 & 3 & 3 & 3 & 3 & 2 & 3 & 3 & 2 & 0 & 0 \\
\hline 2 & M & 72 & 71 & None & 2 & 3 & 3 & 3 & 3 & 0 & & 3 & 3 & 0 & 0 \\
\hline 3 & $M$ & 81 & 71 & None & 2 & 3 & 3 & 2 & 1 & 0 & & 3 & 3 & 0 & 0 \\
\hline 4 & M & 37 & 37 & None & 3 & 2 & 3 & 3 & 3 & 2 & 1 & 0 & & 0 & 0 \\
\hline 5 & M & 54 & 43 & $\mathrm{PD}(2 \times 3)$ & 2 & 3 & 2 & 3 & 2 & 2 & 2 & 2 & 2 & 0 & 0 \\
\hline 6 & M & 22 & 16 & $\mathrm{PD}(2 \times 3)$ & 3 & 3 & 2 & 3 & 2 & 0 & & 0 & & 0 & 0 \\
\hline 7 & $\mathrm{~F}$ & 21 & 20 & $\mathrm{PD}(1 \times 3)$ & 3 & 3 & 3 & 3 & 3 & 2 & 3 & 3 & 2 & 0 & 0 \\
\hline 8 & $M$ & 24 & 16 & $\mathrm{PD}(2 \times 3)$ & 2 & 3 & 3 & 3 & 3 & 2 & 1 & 0 & & 0 & 0 \\
\hline 9 & $\mathrm{~F}$ & 64 & 54 & $\mathrm{PD}(3 \times 3)+$ myotomy & 3 & 3 & 3 & 3 & 3 & 0 & & 3 & 3 & 0 & 0 \\
\hline 10 & M & 31 & 30 & $\mathrm{PD}(1 \times 3)$ & 1 & 0 & & 1 & 3 & 2 & 3 & 0 & & 0 & 0 \\
\hline 11 & $\mathrm{~F}$ & 79 & 43 & PD $(3 \times 3)+$ myotomy & 3 & 3 & 3 & 3 & 3 & 0 & & 3 & 3 & 1 & 2 \\
\hline
\end{tabular}

Oesophageal dilation: 0 , not dilated; 1 , mild (diameter $\leqslant 0.5$ vertebra); 2 , moderate (diameter $0.5-1$ vertebra); 3 , severe (diameter $\geqslant 1$ vertebra). Symptom score: frequency (F): 0, never; 1, 1-3/week; 2, 4-6/week; 3, every day; severity (S): 1, mild; 2, moderate; 3, severe.

$\mathrm{PD}$, pneumatic dilatation (number of sessions $\times$ number of dilatations per session).

term manometric tracings, these studies provided evidence for the occurrence of peristaltic contractions in some patients and high amplitude pressure waves during eating.

Thus far, prolonged ( 24 hour) manometric studies of both the oesophageal body and LOS in achalasia patients have not been carried out. We hypothesised that prolonged monitoring of oesophageal and LOS function might reveal phenomena that have remained undetected in studies using conventional short term manometry. A secondary aim of the study was to explore the relationship between motor phenomena and gastro-oesophageal reflux in achalasia.

\footnotetext{
Methods

PATIENTS

Prolonged combined oesophageal $\mathrm{pH}$ and manometric recordings were performed in 11 patients with symptomatic achalasia (seven men and four women; mean age 46.3 years (range 21-81)) referred to our motility lab. The diagnosis of achalasia had been established by short term manometry using absence of peristalsis in the oesophageal body and absent or incomplete LOS relaxations in response to 10 swallows of $5 \mathrm{ml}$ of water as the most important criteria. ${ }^{9}$ Symptoms associated with achalasia were present for an average period of six years (range 0-36) before enrolment. Three patients had never been treated for achalasia. The other eight patients had undergone one or more series of pneumatic dilatations using polyethylene balloons with a diameter of 30-40 $\mathrm{mm}$ inflated for a period of three minutes at a pressure of $200 \mathrm{~mm} \mathrm{Hg}$. Two patients had undergone a Heller myotomy via laparotomy six and 32 years previous to this study.

Endoscopy excluded other gastrointestinal abnormalities not related to achalasia in all patients. Radiographic examination of the oesophagus was performed which showed a mildly to severely dilated oesophagus in all patients. Severity of dilation was scored on a four point scale in which the diameter of the oesophagus was scored relative to the diameter of the vertebrae: 0 , not dilated; 1 , mild (diameter $\leqslant 0.5$ vertebra); 2 , moderate (diameter $0.5-1$ vertebra); and 3 , severe (diameter $\geqslant 1$ vertebra).
}

Frequency and severity of dysphagia for solids, dysphagia for liquids, retrosternal pain, regurgitation, and heartburn during the week before the study were scored in each patient using a questionnaire. None of the patients was receiving drugs known to influence oesophageal or gastric motility, or gastric acid secretion. Patient characteristics are presented in table 1 .

\section{STUDY PROTOCOL}

Prior to the 24 hour study, all patients underwent a conventional short term manometry of the oesophagus in the supine position.

Prolonged manometric recording was carried out after a 24 hour period during which patients received a liquid diet followed by an overnight fast. During the 24 hour study, patients were in an upright position during the day and were allowed to consume liquids (beverages and liquid meals) only. To test the effect of a meal on LOS pressure, all patients had one standardised meal consisting of a $200 \mathrm{ml}$ nutrient drink (300 kcal, 13\% protein, 39\% carbohydrate, $48 \%$ fat) (Nutridrink, Nutricia, Netherlands). A single standardised liquid meal was used as we did not wish to jeopardise completion of the test by patients and we wanted to avoid the possibility of prolonged oesophageal retention of solid food particles. Patients were instructed to complete a diary and to use event keys on the data logger indicating the times of meals and occurrence of heartburn and retrosternal pain.

\section{EQUIPMENT}

Conventional short term manometric recording of the oesophagus and LOS was performed using the portable perfused manometric system described below or using a seven lumen assembly (OD $4.7 \mathrm{~mm}$, ID $0.74 \mathrm{~mm}$ ) with an incorporated $6 \mathrm{~cm}$ long sleeve (Dentsleeve Pty Ltd, Adelaide, South Australia). Pharyngeal and oesophageal sideholes were localised at 20 and $25 \mathrm{~cm}$ and 5,10 , and $15 \mathrm{~cm}$ proximal to the sleeve, respectively. Intragastric pressure was measured using a sidehole $1 \mathrm{~cm}$ below the sleeve. The assembly was perfused with degassed water at a rate of $0.45 \mathrm{ml} / \mathrm{min}$ using a low compliance pneumohydraulic infusion pump and hydraulic flow restrictors (Dentsleeve Pty Ltd). 
Prolonged manometric recording of the pharynx, oesophagus, LOS, and stomach was performed with a water perfused, micromanometric, 12 channel silicone rubber assembly (Dentsleeve Pty Ltd). The catheter (OD 3.5 $\mathrm{mm}$, ID $0.4 \mathrm{~mm}$ ) incorporated four pharyngeal sideholes $(24,26,28$, and $30 \mathrm{~cm}$ proximal to the proximal border of the sleeve) and three oesophageal sideholes (4, 9, and $14 \mathrm{~cm}$ proximal to the proximal border of the sleeve), a reversed perfused sleeve with one sidehole on its proximal border, and one intragastric sidehole $\left(2 \mathrm{~cm}\right.$ distal to the sleeve). ${ }^{24} \mathrm{~A}$ guidewire placed in the central lumen of the catheter was used to manoeuvre the flexible catheter through the LOS. The manometric assembly was positioned with the proximal border of the sleeve at $1 \mathrm{~cm}$ proximal to the proximal border of the LOS. After correct positioning of the manometric assembly the sidehole on top of the sleeve was capped off and the guidewire was removed. In addition, the two optimal pharyngeal sideholes were detected and the other two were also capped off.

Pressures were recorded using external pressure transducers (Abbott, Chicago, Illinois, USA). Hydraulic flow restrictors were used to reduce water flow to a rate of $0.08 \mathrm{ml} / \mathrm{min}$ (Dentsleeve Pty Ltd). The flow restrictors and pressure transducers were mounted on a belt. ${ }^{25}$ The system was connected to a locally developed pneumohydraulic low compliance water pump consisting of a small gas cylinder and a water reservoir of $350 \mathrm{ml}^{26}$ The water pump was carried in a backpack. Bench tests showed that the rate of rise of the manometric system was $>21.5 \mathrm{kPa} / \mathrm{s} .{ }^{27}$ Oesophageal $\mathrm{pH}$ was recorded using a glass electrode (model LOT 440; Ingold AG, Urdorf, Switzerland) positioned $5 \mathrm{~cm}$ above the proximal border of the LOS. Both catheters were connected to a digital data logger (MMS; Enschede, the Netherlands) which sampled pressure signals at a rate of $4 \mathrm{~Hz}$, except for pharyngeal pressure signals which were sampled at a rate of $8 \mathrm{~Hz}$. The $\mathrm{pH}$ signal was sampled with a frequency of $1 \mathrm{~Hz}$.

Before the start of the recording, the $\mathrm{pH}$ electrode and manometric assembly were calibrated. The $\mathrm{pH}$ electrode was calibrated at $37^{\circ} \mathrm{C}$ using $\mathrm{pH} 4.0$ and 7.0 buffer solutions (Radiometer analytical A/S; Bagsvaerd, Copenhagen, Denmark) and the manometric assembly was calibrated at 0 and $50 \mathrm{~cm} \mathrm{H}_{2} \mathrm{O}(0$ and $5.0 \mathrm{kPa}$ ).

DATA ANALYSIS

Twenty four hour pressure signal sets were visually examined in order to detect complete LOS relaxations, high amplitude oesophageal pressure waves, and retrograde waves. In addition, end expiratory LOS pressure was measured for the 24 hour period, taking visual mean values of consecutive five minute stretches, as described below. In the analysis of the 24 hour data, four periods were distinguished which will be referred to as perprandial, postprandial, fasting, and night time periods. The perprandial period consisted of all periods during drinking; the postprandial period comprised all one hour periods following individual perprandial periods. The fasting period consisted of all remaining periods during the day, and the night time period was the period between retiring and waking up.

LOS PRESSURE MEASUREMENT

Basal end expiratory LOS pressure, referenced to intragastric pressure, was determined at five minute intervals by taking a visual mean value of the tracing during this period after exclusion of relaxations and contractions of the LOS. Recorded LOS pressure was corrected for the changes caused by alterations in body position based on the following results. Bench tests showed identical increments in pressures recorded from the sidehole at the proximal border of the sleeve and the sleeve itself with the assembly in the horizontal and vertical position. A pilot study in four healthy volunteers showed that a change from the supine towards the sitting position increased the pressure in the distal oesophagus (measured by the sidehole at the proximal site of the sleeve) by $0.2 \mathrm{kPa}$ more than the pressure measured by the intragastric sidehole. Therefore, basal end expiratory LOS pressure in the sitting position was defined as the pressure measured in the sleeve relative to the pressure recorded by the gastric sidehole minus $0.2 \mathrm{kPa}$.

\section{COMPLETE LOS RELAXATIONS}

All complete LOS relaxations that occurred during the prolonged recording were detected manually. These were defined as LOS relaxations with a corrected nadir pressure $\leqslant 0.2 \mathrm{kPa}$ lasting for at least three seconds. For each patient the mean duration of complete LOS relaxations, defined as the period during which LOS pressure was at the nadir level, was analysed. During each complete LOS relaxation, inhibition of the activity of the crural diaphragm, as recorded by the reversed perfused sleeve, was assessed. ${ }^{24}$ Inhibition of the crural diaphragm was defined as a sudden decrease in the amplitude of respiratory oscillations of more than $50 \% .^{28}$ Complete LOS relaxations were categorised into those that were swallow associated (pharyngeal contraction in a time window from four seconds before to two seconds after the onset of LOS relaxation) and those that were not. In addition, LOS relaxations which fulfilled all of the criteria of a nonswallow related transient LOS relaxation (TLOSR) were identified using the criteria of Holloway and colleagues. ${ }^{29}$

The characteristics of oesophageal pressure waves associated with complete LOS relaxations were determined. These were categorised as either associated with a pharyngeal contraction or as spontaneous pressure waves defined as oesophageal pressure waves that occurred in the absence of a swallow in the preceding seven seconds. This definition was based on data obtained from 10 healthy volunteers showing that the mean time $+2 \mathrm{SD}$ for a swallow induced pressure wave in the distal channel was 6.23 seconds (unpublished data). For each detected pressure wave it was determined 


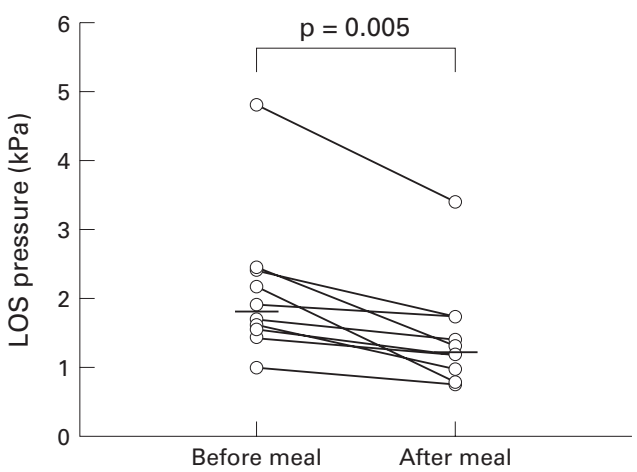

Figure 1 Effect of a liquid nutrient meal on basal lower oesophageal sphincter (LOS) pressure. Basal LOS pressures were significantly lower after the meal than those recorded during the one hour period preceding the meal.

whether the contraction was peristaltic, simultaneous, non-transmitted (defined as a wave in one or two channels only), repetitive, or retrograde, using the onset of the pressure wave as the reference point. In addition, the amplitudes and durations of the pressure waves in the proximal, mid, and distal oesophagus were determined (14,9, and $4 \mathrm{~cm}$ above the sleeve). The proportion of oesophageal pressure waves characterised by more than one peak was calculated.

HIGH AMPLITUDE OESOPHAGEAL PRESSURE WAVES The complete 24 hour recordings were examined in order to identify oesophageal pressure waves with an amplitude $>10 \mathrm{kPa}$. Amplitude, duration, and mode of propagation of these contractions were determined.

EFFECT OF A MEAL ON LOS PRESSURE

To investigate the effect of a caloric nutrient drink on LOS pressure, sphincter pressure during the first hour after the intake of the drink was compared with that recorded during the one hour period before the meal.

RELATIONSHIP WITH PHASE III AND LOS PRESSURE Participation of the stomach in phase III of the interdigestive MMC is characterised by strong contractile activity of the antrum at the maximum frequency of three per minute.
These strong antral contractions can often be detected in pressure recordings from the proximal stomach. In the 24 hour recordings obtained from our patients, all periods suggestive of phase III-that is, short periods with intragastric pressure variations of more than 1 $\mathrm{kPa}$ at a frequency of three per minute-were identified. LOS pressures during these periods were compared with LOS pressures during the 15 minute period afterwards (first part of phase I).

\section{INCOMPLETE LOS RELAXATIONS}

A randomly selected 30 minute period during fasting was used for detection of incomplete LOS relaxations. It was determined whether these relaxations were swallow associated or spontaneous, and their duration was measured. The same 30 minute period was used to obtain baseline values for amplitude, duration, and association with swallowing of oesophageal pressure waves.

\section{ACID REFLUX}

Automated analysis of oesophageal $\mathrm{pH}$ data to measure oesophageal acid exposure was expressed as percentage of time with $\mathrm{pH}<4$. Acid reflux episodes were detected visually. These were defined as a drop in oesophageal $\mathrm{pH}$ of at least one unit at a rate of $>1 \mathrm{pH}$ unit $/ 6 \mathrm{~s}$, and with a duration of $>3 \mathrm{~s}$. In addition, $\mathrm{pH}$ drifts, defined as a gradual decrease ( $>6 \mathrm{~s} / \mathrm{pH}$ unit) to $\mathrm{pH}<4$, were detected. For each event the underlying reflux mechanism was determined.

STATISTICAL ANALYSIS

Data showed a non-parametric distribution and therefore non-parametric tests were used in the statistical analysis. For most comparisons the Friedman ANOVA was used, followed by the Wilcoxon signed rank test in the event of significance. The effect of the nutrient drink on LOS pressure was analysed using the Wilcoxon signed rank test.

Unless stated otherwise, data are expressed as medians and interquartile ranges; $p<0.05$ was accepted as significant.
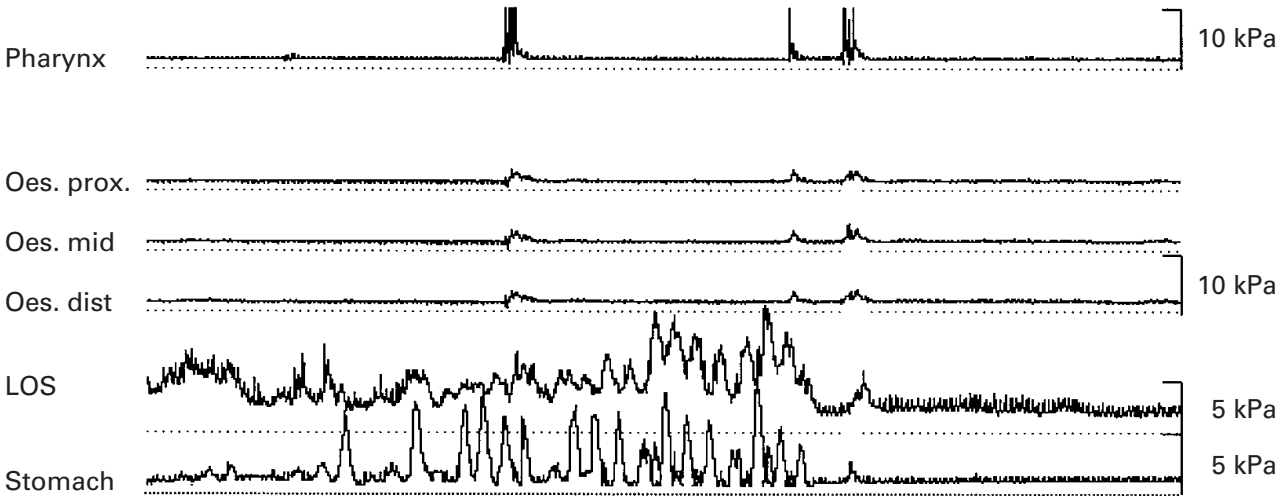

\section{2 minutes}

Figure 2 Typical example of basal lower oesophageal sphincter (LOS) pressure during phase III of the migrating motor complex cycle. The signal obtained from the intragastric sidehole shows a 3/minute rhythm. Intragastric pressure peaks exceed basal LOS pressure. Basal LOS pressure is higher during phase III than during the subsequent phase I. 


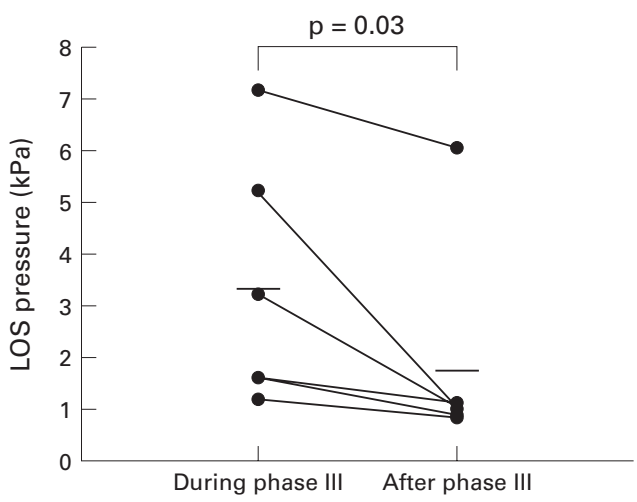

Figure 3 Effect of migrating motor complex (MMC) cycle activity on basal lower oesophageal sphincter (LOS) pressure. LOS pressure was significantly higher during phase III of the MMC cycle than during the 15 minute period afterwards (phase I).

\section{Results}

During short term manometry all patients showed aperistalsis of the oesophageal body and incomplete LOS relaxations. The short term manometric recording of one patient was lost due to a technical failure. Mean recording time for prolonged manometry was 20.8 hours (range 8.2-23.2). One patient (patient No 11) was excluded from analysis of complete LOS relaxations because of an error during the zeroing procedure. In patient No 9, 3.5 hours of the recording, including the standardised meal, was excluded from the analysis because of technical problems. In one patient (patient No 3), recording was stopped before night time at the patient's request.

\section{LOS PRESSURE}

LOS pressures recorded during the pre-meal period of the 24 hour recording were similar to LOS pressures recorded during short term manometry $(1.8(1.5-2.3) \mathrm{kPa} v 2.1(1.4-2.8)$ $\mathrm{kPa}$, respectively; $\mathrm{NS}$ ).

In all patients, LOS pressures were lower after the meal than during the one hour period before the meal (fig 1). LOS pressures during the night were significantly lower than LOS pressures recorded before the meal (1.3 $(1.1-1.6) \mathrm{kPa} v 1.8(1.5-2.3) \mathrm{kPa}$, respectively; $\mathrm{p}=0.038)$.
Gastric pressure variations suggestive of phase III of the interdigestive MMC were observed in six patients (fig 2). In these six patients a total of 10 of these periods were detected. Basal LOS pressure was significantly higher during these periods than during the 15 minute period afterwards (fig 3 ).

COMPLETE LOS RELAXATIONS AND ASSOCIATED OESOPHAGEAL PRESSURE WAVES

In seven patients (patient Nos 1, 2, 5, 7, 8, 9, and 10), complete LOS relaxations occurred with a frequency of $0.48(0.46-0.61)$ per hour. In total, 113 complete LOS relaxations were observed (fig 4). Inhibition of the crural diaphragm was observed during all of these 113 complete LOS relaxations.

The incidence of complete LOS relaxations was significantly higher during the perprandial period than during the night $(0.74 / \mathrm{h}(0.64-$ 1.63) $v 0.13 / \mathrm{h}(0-0.54)$, respectively; $\mathrm{p}<0.05)$. Similarly, complete LOS relaxations occurred more frequently during the postprandial period than during the night $(1.00(0.87-1.29) v 0.13$ $(0-0.54)$, respectively; $\mathrm{p}<0.05)$.

Complete LOS relaxations had a significantly longer duration than incomplete LOS relaxations (10.8 s (8.4-12.9) v $2.8 \mathrm{~s}$ (2.1-3.0); $\mathrm{p}=0.01)$. In addition, complete LOS relaxations lacked an association with a swallow more often than incomplete LOS relaxations $(70.0 \%$ (45.0-91.4) v 15.6\% (14.1-22.4)).

Fifty seven per cent $(42.2-80.2 \%)$ of complete LOS relaxations not only occurred without a preceding swallow but also fulfilled all other criteria of a TLOSR (fig 5).

In one patient, $44 \%$ of complete LOS relaxations were not associated with an oesophageal pressure wave. In the other patients complete LOS relaxations were always associated with an oesophageal pressure wave (fig 4). These pressure waves had significantly higher amplitudes than those recorded during short term manometry and during the 30 minute baseline period of the prolonged manometric recording (fig 6). Mean durations of the oesophageal pressure waves during complete LOS relaxations were also significantly longer than mean durations of the oesophageal

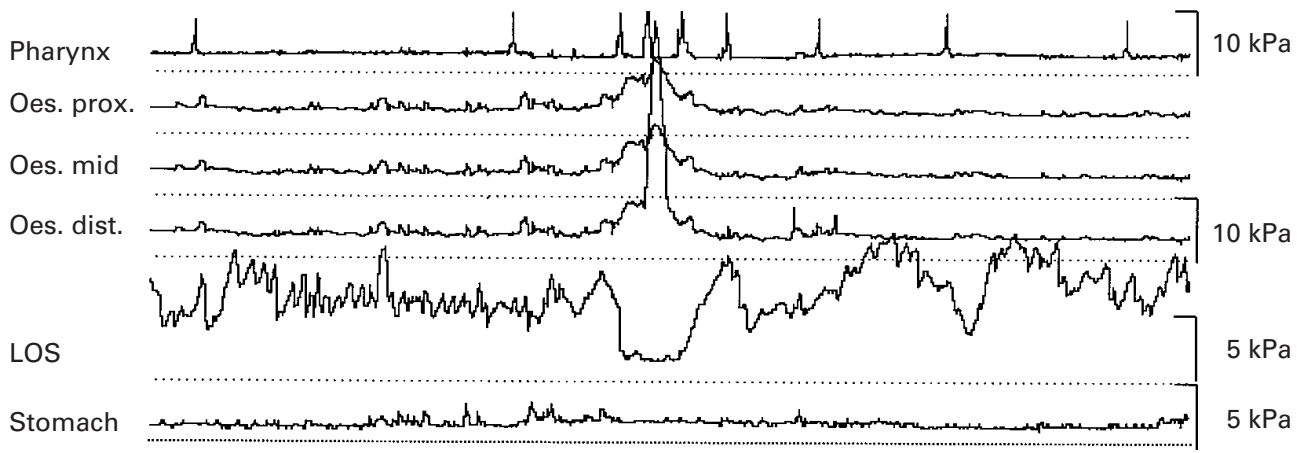

1 minute

Figure 4 Example of a complete lower oesophageal sphincter (LOS) relaxation. This complete LOS relaxation was associated with a common cavity phenomenon and a high amplitude pressure wave $(34.2 \mathrm{kPa})$ in the distal oesophagus. Several subsequent swallows were not followed by oesophageal pressure waves or LOS relaxation. 


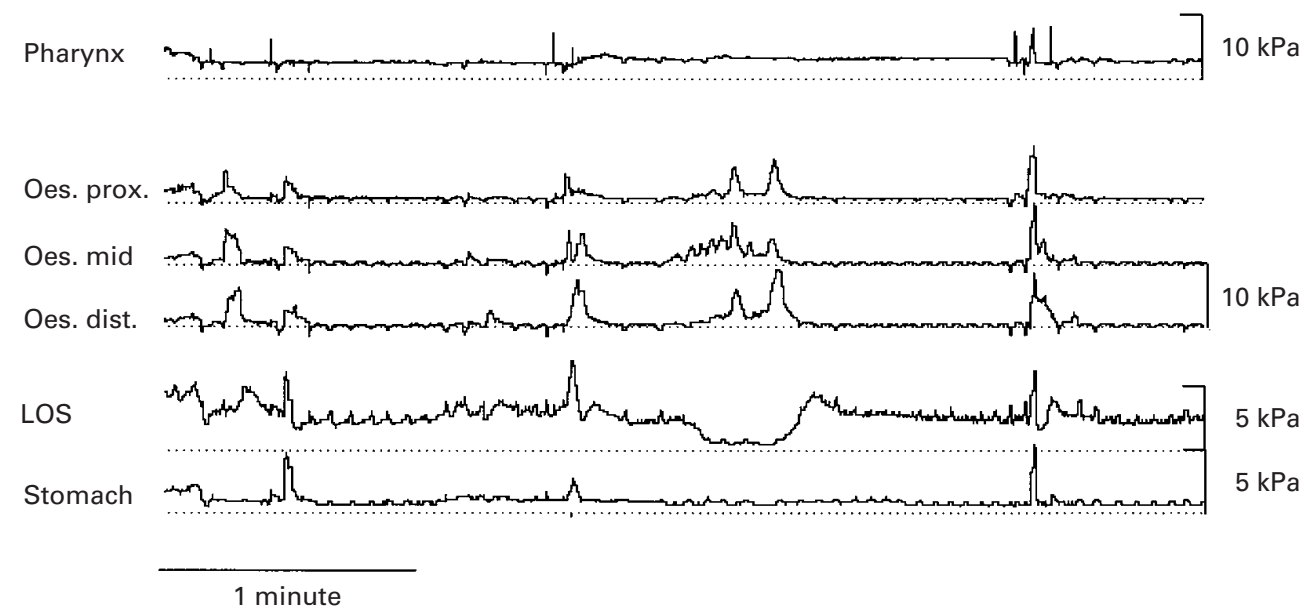

Figure 5 Transient lower oesophageal sphincter (LOS) relaxation. This relaxation met the criteria of a transient LOS relaxation.

pressure waves during the short term and 30 minute baseline period (table 2).

The proportion of spontaneous oesophageal pressure waves was significantly higher during complete LOS relaxations than during the 30 minute baseline period $(55.6 \%(37.8-68.6) v$ 0\% (0-6.9), respectively; $\mathrm{p}<0.02)$.

Pressure waves associated with complete LOS relaxations were multipeaked more often than pressure waves that were not associated with complete LOS relaxations $(72.7 \%$ (25.082.2) v $0 \%(0-0)$, respectively; $\mathrm{p}<0.05)$.

HIGH AMPLITUDE OESOPHAGEAL PRESSURE WAVES The prolonged manometric tracings of six patients showed oesophageal pressure waves with an amplitude $>10 \mathrm{kPa}$ in the proximal,

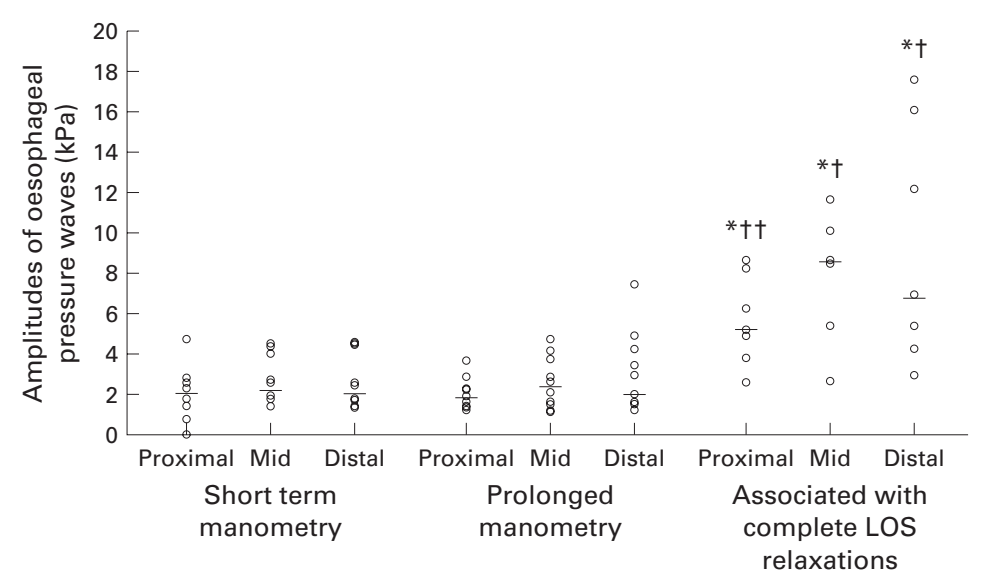

Figure 6 Amplitudes of oesophageal pressure waves during short term and prolonged manometry and of those associated with a complete lower oesophageal sphincter (LOS) relaxation. Oesophageal pressure waves associated with complete LOS relaxations had a higher amplitude in the proximal, mid, and distal oesophagus compared with amplitudes during short term and prolonged manometric recording. ( ${ }^{\star} p<0.02 v$ prolonged manometry; $t p<0.03, t+p<0.05$ v short term manometry).

Table 2 Duration of oesophageal pressure waves recorded during short term and prolonged manometry and during complete lower oesophageal sphincter (LOS) relaxations

\begin{tabular}{llll}
\hline & $\begin{array}{l}\text { Wet swallows } \\
\text { (short term manometry) }\end{array}$ & $\begin{array}{l}\text { Fasting period } \\
\text { (prolonged manometry) }\end{array}$ & $\begin{array}{l}\text { Complete LOS relaxations } \\
\text { (prolonged manometry) }\end{array}$ \\
\hline No patients & 10 & 11 & 7 \\
Duration proximal (s) & $5.4(4.7-6.9)$ & $4.5(3.9-5.3)$ & $8.8(7.5-15.5)^{\mathrm{a}}$ \\
Duration mid (s) & $5.4(4.7-6.9)$ & $4.3(4.2-5.5)$ & $12.1(9.3-16.5)^{\mathrm{b}}$ \\
Duration distal (s) & $5.4(4.7-6.9)$ & $5.2(4.4-5.4)$ & $14.1(12.3-17.2)^{\mathrm{a}}$ \\
\hline
\end{tabular}

${ }^{\mathrm{a}} \mathrm{p}<0.05$ versus short term manometry; ${ }^{\mathrm{b}} \mathrm{p}<0.02$ versus prolonged manometry. mid, or distal oesophagus. In these patients (Nos 1，2，3，5，9, and 10), the highest amplitudes were 27.2, 43.2, 50, 33.3, 23.2, and $15.5 \mathrm{kPa}$, respectively, being 13 (13-13) times higher than the mean amplitude of the oesophageal pressure waves during short term manometry. The median incidence per hour was 2.57 (1.46-4.70). There was no association between the period of the day (perprandial, postprandial, fasted, and night time periods) and the incidence of these pressure waves. Their frequency tended to be higher in patients with mild oesophageal dilatation $(\mathrm{p}=0.08)$. In $14.7 \%(12.7-58.3)$, these high amplitude oesophageal pressure waves were associated with complete LOS relaxations: $8.8 \%(7.7-11.4)$ began within three seconds before the onset of a complete relaxation, $6.4 \%$ (0-3.45) coincided with the onset of a complete LOS relaxation, respectively.

RETROGRADE OESOPHAGEAL PRESSURE WAVES In four patients (patient Nos 1, 5, 9, and 10), retrograde oesophageal pressure waves were detected during the prolonged recording. All of these retrograde pressure waves were characterised by a higher velocity from the distal to mid than from the mid to proximal level (2.3 $\mathrm{cm} / \mathrm{s}(1.8-2.7) v 0.73 \mathrm{~cm} / \mathrm{s}(0.66-0.90))$. All retrograde pressure waves had an amplitude $>10 \mathrm{kPa}$ and most of these were associated with a complete LOS relaxation. An example of a retrograde pressure wave is shown in fig 7 .

OESOPHAGEAL ACID EXPOSURE

Four patients (patient Nos 2, 4, 5, and 9) showed acid reflux episodes. In the same patients $\mathrm{pH}$ drifts were observed. In total, 18 acid reflux events and $21 \mathrm{pH}$ drifts were observed. Ninety five per cent of the acid reflux episodes occurred during the day. In contrast, $\mathrm{pH}$ drifts were mainly observed during the night $(74 \%)$.

In the four patients who had acid reflux, median time with oesophageal $\mathrm{pH}<4$ was $6.4 \%(4.2-9.3)$. During the upright and supine periods, the percentage of time with oesophageal $\mathrm{pH}<4$ was $8.5 \%(5.2-13.6)$ and $2.8 \%$ (0.9-4.4), respectively. Six of the 18 reflux 


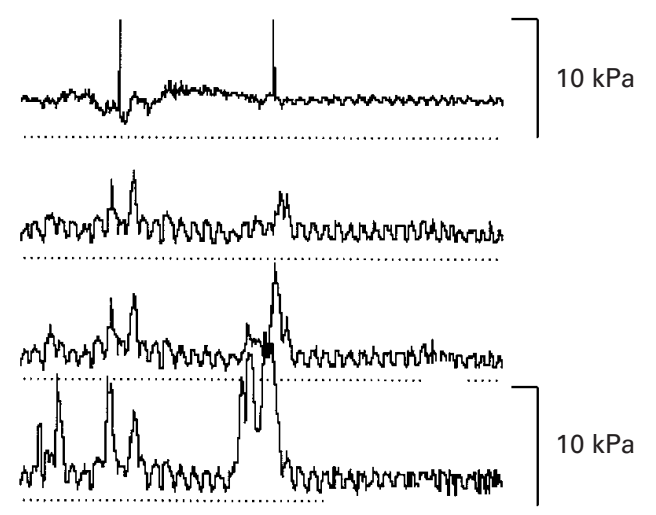

1 minute

Figure 7 Example of a retrograde oesophageal pressure wave.

events were associated with complete LOS relaxations, five with straining, four occurred during incomplete LOS relaxations, and three during low basal LOS pressure.

\section{Discussion}

This is the first study in which prolonged manometric recording of the pharynx, oesophagus, LOS, and stomach was used in achalasia patients.

Several new observations were made: (1) seven of the 11 achalasia patients occasionally had complete LOS relaxations; (2) LOS pressure showed considerable fluctuations associated with a meal and phase III of the MMC; (3) high amplitude oesophageal pressure waves occurred in achalasia patients who had a mildly to severely dilated oesophagus; and (4) retrograde pressure waves were observed in a subset of patients with achalasia.

Although eight of the 11 achalasia patients had been treated previously, all had recurrent complaints of dysphagia and the short term manometric study showed complete aperistalsis of the oesophageal body and incomplete LOS relaxation. Whereas none of the achalasia patients had complete LOS relaxations during the short term manometric recordings, prolonged oesophageal manometry demonstrated the intermittent occurrence of complete LOS relaxations in seven of the 11 patients, with a frequency of $0.5 / \mathrm{h}$. These relaxations were most frequently present during meals and in the postprandial period, which might indicate that complete relaxations of the LOS are provoked by food passage or food retention in the oesophageal body. As with complete LOS relaxations in healthy subjects, all complete LOS relaxations in patients with achalasia were associated with inhibition of the crural diaphragm. ${ }^{30}$ The oesophageal motor activity observed during complete LOS relaxations in our achalasia patients is in contrast with inhibition of the oesophageal body during TLOSRs in healthy subjects and gastro-oesophageal reflux patients and suggests separate neural events in the LOS and oesophageal body. ${ }^{31}$

One could argue that the complete LOS relaxations observed during prolonged recordings in our achalasia patients were artefacts.
Complete LOS relaxations could be due to shortening of the oesophagus occurring during the high amplitude pressure waves, causing displacement of the sleeve towards the stomach. However, recently Mazzadi et al described almost absence of oesophageal shortening in achalasia patients. ${ }^{32}$ In addition, the gradual rather than abrupt fall and rise in LOS pressure, and the fact that the observed LOS relaxations lasted considerably longer than the high amplitude oesophageal pressure waves, also argue against this hypothesis. Furthermore, LOS pressures recorded immediately before and after the complete relaxation were relatively high, indicating a tight grip of the sphincter complex on the sleeve sensor. It would therefore be more likely that the catheter curls up in the widened oesophagus during oesophageal body shortening than that the sleeve sensor enters the stomach during these events.

Complete LOS relaxations have been observed previously in other manometric and radiographic studies in patients with achalasia but in these studies complete LOS relaxations were short in duration and "functionally inadequate" ${ }^{11-13}$ It was speculated that patients in whom these complete LOS relaxations occurred had an early stage of achalasia as these patients were younger, had a shorter duration of dysphagia, and less oesophageal dilatation. ${ }^{11} 12$ Achalasia patients in whom we observed complete LOS relaxations did not fit this profile. Furthermore, the complete LOS relaxations observed in our study had a long duration. Fifty seven per cent of complete LOS relaxations fulfilled the criteria of a transient LOS relaxation - that is, they were not swallow related.

The mechanism through which complete LOS relaxations in achalasia are triggered remains unclear. It is unlikely that complete LOS relaxations are caused by mechanical distension of the oesophageal body as balloon distension of the oesophageal body in patients with achalasia does not result in a complete LOS relaxation. ${ }^{33}$ Moreover, in achalasia patients, transient LOS relaxations cannot be induced by gastric distension. ${ }^{34}$

Although complete LOS relaxations were associated with inhibition of the activity of the crural diaphragm, acid reflux rarely occurred during these relaxations. It might be that the oesophageal pressure waves associated with complete LOS relaxations prevented the occurrence of acid reflux. Another explanation for the low incidence of reflux events during complete LOS relaxations might be impaired gastric acid secretion in achalasia patients. ${ }^{35} 36$

In this study we observed that LOS pressure in achalasia patients varied during the day in a manner similar to that described in healthy subjects. ${ }^{37} 38$ The most striking pressure variations were related to meal ingestion and to phase III of the interdigestive migrating complex. As described previously in two patients by Holloway et al, we observed that LOS pressure was significantly higher during phase III. ${ }^{20}$ Variations in LOS pressure associated with the MMC cycle have been observed 
in healthy subjects, dogs, and opossums. ${ }^{39-41}$ The increase in LOS pressure during phase III can be blocked by atropine, indicating that cholinergic input is a prerequisite for this phenomenon. ${ }^{40}{ }^{42}$ Our observation that in achalasia patients LOS pressure is MMC cycle dependent indicates that the excitatory cholinergic innervation of the LOS is still functional in these patients. ${ }^{20} 43$

Another new observation was that in achalasia patients LOS pressure decreased in the postprandial period, as in healthy subjects and patients with gastro-oesophageal reflux. ${ }^{37} 3844$ Although several neuronal and hormonal mechanisms may play a role in the postprandial decrease in LOS pressure, cholecystokinin release induced by fat in the meal has been put forward as the most important mechanism..$^{38} 45$ However, in patients with achalasia, a paradoxical increase in LOS pressure after cholecystokinin infusion has been reported. ${ }^{1}$ Studies in achalasia patients have shown that LOS pressure is decreased by somatostatin, secretin, vasoactive intestinal polypeptide, and opioids. ${ }^{14-19}$ It might therefore be that one of these or other intestinal hormones or neurotransmitters are responsible for decreased LOS pressure after a meal through inhibition of cholinergic pathways or by acting directly on the LOS.

High amplitude oesophageal pressure waves were observed in six of our 11 patients. This finding was surprising as none of the short term manometric recordings showed pressure waves with amplitudes exceeding $4.5 \mathrm{kPa}$. Although high amplitude pressure waves tended to occur less frequently in patients with a more severely dilated oesophagus, some of the patients with high amplitude pressure waves had a markedly dilated oesophagus. It is likely that the low incidence of these strong contractions is the most important explanation for these contractions being undetected during short term conventional manometry. It could also be that the nature of the stimulus plays a role as during conventional stationary manometry only $5 \mathrm{ml}$ boluses of water were given, whereas during prolonged recording more substantial liquid meals were taken. This hypothesis is in agreement with a study by Stuart et al who observed high amplitude oesophageal pressure waves in untreated achalasia patients only during a solid meal. ${ }^{21}$ However, we feel that it is unlikely that the observed high amplitude pressure waves were associated with or caused by retention of fluid in the oesophagus because there was an equal distribution over the various periods of the day and oesophageal baseline elevations were rarely seen in association with high amplitude waves.

Another unexpected finding was the evidence of retrograde pressure waves in four of the 11 achalasia patients. In their fluoroscopic study, Lu et al occasionally observed retrograde propagation of circular oesophageal contractions in opossums with a dilated oesophagus. ${ }^{46}$ To our knowledge retrograde pressure waves have never been described in achalasia patients. Our observations do not allow conclusions regarding the mechanism underlying this phenomenon. It is likely however that altered innervation of the oesophageal muscle is involved.

In summary, in this study using prolonged water perfused manometry of the oesophagus and LOS, several unexpected manometric findings were made in 11 patients with achalasia which were not observed during short term manometry. Complete LOS relaxations with prolonged duration were found in the majority of patients with achalasia. LOS pressures recorded showed fluctuations during prolonged recording which were related to meals and the MMC cycle, and the oesophageal body of achalasia patients appeared to be able to generate high amplitude and retrograde pressure waves. The importance of our findings for clinical practice needs to be explored in future studies. However, we do not believe that our observations should be interpreted as indicative of the invalidity of established manometric criteria for the diagnosis of achalasia. One should realise that the complete LOS relaxations observed in our achalasia patients occurred very infrequently and that it is highly unlikely that a complete LOS relaxation is recorded during standard motility testing.

1 Dodds WJ, Dent J, Hogan WJ, et al. Paradoxical lower esophageal sphincter contraction induced by esophageal sphincter contraction induced by cholecystokinin-octapeptide in

2 Cassella RR, Brown AL, Sayre GP, et al. Achalasia of the esophagus: pathologic and etiologic considerations. Ann Surg 1964;160:474-87

3 Adams CWM, Brain RHF, Trounce JR. Ganglion cells in achalasia of the cardia. Virchows Arch A Pathol Anat Histol 1976;372:75-9.

4 Aggestrup S, Uddman R, Sundler F, et al. Lack of vasoactive intestinal polypeptide nerves in esophageal achalasia. Gastroenterology 1983;64:924-7.

5 Qualman SJ, Haupt HM, Yang P, et al. Esophageal Lewy bodies associated with ganglion cell loss in achalasia. Gastroenterology 1984;87:848-56.

6 Sigala S, Missale G, Villanacci V, et al. Different neurotransmitter systems are involved in the development of esopha-

7 De Giorgio R, Di Simone MP, Stanghellini V, et al. Esophageal and gastric nitric oxide synthesizing innervation in primary achalasia. Am f Gastroenterol 1999;94:2357-62.

mary achalasia. Am f Gastroenterol 1999;94:2357-62.
8 Friesen DL, Henderson RD, Hanna W. Utrastructure of the Friesen DL, Henderson RD, Hanna W. Utrastructure of the
esophageal muscle in achalasia and diffuse esophageal spasm. Am f Clin Pathol 1983;79:319-25.

9 Benjamin SR, Richter JE, Cordova CM, et al. Prospective manometric evaluation with pharmacologic provocation of patients with suspected esophageal motility dysfunction. Gastroenterology 1983;84:893-901.

10 Wong RKH, Mazure R. Achalasia. In: Castell DO, Richter JE, eds. The Esophagus. Philadelphia: Lippincott Wiliams and Wilkins, 1999:185-213.

11 Katz PO, Richter JE, Cowan R, et al. Apparent complete lower esophageal sphincter relaxation in achalasia. Gastroenterology 1986;90:978-83.

12 Ott DJ, Richter JE, Chen YM, et al. Radiographic and manometric correlation in achalasia with apparent relaxation of the lower esophageal sphincter. Gastrointest Radiol 1989;14:1-5.

13 Mearin F, Malagelada J-R. Complete lower esophageal phincter relaxation observed in some achalasia patients is functionally inadequate. Am F Physiol 2000;278:G376-83.

14 Greco AV, Bianco A, Altmonte L, et al. Effect of somatostatin on lower esophageal sphincter (les) pressure and serum gastrin in normal and achalasia subjects. Horm Metab Res 1982;14:26-8 .

15 Guelrud M, Rossiter A, Souney PF, et al. Transcutaneous electrical nerve stimulation decreases lower esophageal sphincter pressure in patients with achalasia. Dig Dis $\mathrm{Sci}$ 1991;36:1029-33.

16 Guelrud M, Rossiter A, Souney PF, et al. The effect of vasoactive intestinal polypeptide on the lower esophageal sphincter in achalasia. Gastroenterology 1992;103:377-82.

17 Penagini R, Bartesaghi B, Zannini P, et al. Lower oesophageal sphincter hypersensitivity to opioid receptor stimulation in patients with idiopathic achalasia. Gut 1993; 34:16-20.

18 Sekiyama N, Kakumoto Y, Nakagawa S, et al. Studies on exogenous and endogenous interaction of gastrin and secretin in case of achalasia. Gastroenterol fpn 1997;12:3959. 
19 Miyata M, Sakamoto T, Hashimoto T, et al. Effect of secretin on lower esopho tin on lower esophageal sphincter pressure in patients with

20 Holloway R, Dodds WJ, Helm JF, et al. Integrity of cholinergic innervation to the lower esophageal sphincter in achalasia. Gastroenterology 1986;90:924-9.

21 Stuart RC, Byrne PJ, Lawlor P, et al. Meal area index: a new technique for quantitative assessment in achalasia by ambulatory manometry during eating. Br F Surg 1992;79 1162-6.

22 Di Martino N, Bortolotti M, Izzo G, et al. 24-hour esophageal ambulatory manometry in patients with achalasia of the esophagus. Dis Esophagus 1997;10:121-7.

23 Tover JA, Prieto G, Molina M, et al. Esophageal function in achalasia: preoperative and postoperative manometric studies. F Pediatr Surg 1998;33:834-8.

24 Sivri B, Mittal RK. Reverse-perfused sleeve: an improved device for measuring sphincteric function of the crural diadevice for measuring sphincteric function
phragm. Gastroenterology 1991;101:962-9.

25 Samsom M, Smout AJPM, Hebbard G, et al. A novel portable perfused manometric system for recording of small intestinal perfused manometric system for recording of sma

26 van Herwaarden MA, Samsom M, Akkermans LMA, et al. Prolonged recording of esophageal and lower esophageal sphincter pressure using a portable manometric system. Neurogastroenterol Motil 2001:13:111-19.

27 Dent J. Dentsleeve Luminal Devices Catalogue. Adelaide, Australia; Fire Starr Press, 1998.

28 Van Herwaarden MA, Samsom M, Smout AJPM. Excess gastroesophageal reflux in patients with hiatus hernia is caused by mechanisms other than transient LES relaxations. Gastroenterology 2000;119:1439-46.

29 Holloway RH, Penagini R, Ireland AC. Criteria for objective definition of transient lower esophageal sphincter relaxation. Am F Physiol 1995;268:G128-33.

30 Mittal RK, Fisher MK. Electrical and mechanical inhibition of the crural diaphragm during transient relaxation of the lower esophageal sphincter. Gastroenterology 1990;99: lower esop-8.

31 Dent J, Holloway RH, Toouli J, et al. Mechanisms of lower oesophageal sphincter incompetence in patients with symp-
tomatic gastrooesophageal reflux. Gut 1998;29:1020-8.

32 Mazzadi S, Sifrim D, Salis G, et al. Esophageal shortening in idiopathic achalasia and Chagas' disease. Gastroenterology 1999;116:A1083.

33 Paterson WG. Esophageal and lower esophageal sphincter response to balloon distention in patients with achalasia. Dig Dis Sci 1997;42:106-12.
34 Holloway RH, Wyman JB, Dent J. Failure of transient lower oesophageal sphincter relaxation in response to gastric distension in patients with achalasia: evidence for neural mediation of transient lower oesophageal sphincter relaxations. Gut 1989;30:762-7.

35 Dooly CP, Taylor IL, Valenzuela JE. Impaired acid secretion and pancreatic polypetide release in some patients with achalasia. Gastroenterology 1983;84:809-13.

36 Csendes A, Smok G, Braghetto I, et al. Histological studies of Auerbach's plexus of the oesophagus, stomach, jejunum and colon in patients with achalasia of the esophagus; correlating with gastric acid secretion, presence of partietal cells and gastric emptying of solids. Gut 1992;33:150-4

37 Schoeman MN, Tippett MD, Akkermans LMA, et al. Mechanisms of gastroesophageal reflux in ambulant healthy human subjects. Gastroenterology 1995;108:83-91.

38 Dent J, Dodds WJ, Friedman RH, et al. Mechanism of gastroesophageal reflux in recumbent asymptomatic human subjects. F Clin Invest 1980;65:256-67.

39 Dent J, Dodds WJ, Sekiguchi T, et al. Interdigestive phasic contractions of the human lower esophageal sphincter. Gastroenterology 1983;84:453-60.

40 Hall KE, Greenberg GR, El-sharkawy TY, et al. Relationship between porcine motilin-induced migrating motor complex-like activity, vagal integrity, and endogenous motilin release in dogs. Gastroenterology 1884;87:76-85.

41 Holloway RH, Blank E, Takahashi I, et al. Variability of lower esophageal sphincter pressure in the fasted unanesthetized opossum. Am f Physiol 1985;248:G389-406

42 Holloway R, Blank E, Takahashi I, et al. Motilin: a mechanism incorporating the opossum lower esophageal sphincter into the migrating motor complex. Gastroenterology 1985;89:507-15.

43 Tottrup A, Forman A, Funch-Jensen P, et al. Effects of postganglionic nerve stimulation in oesophageal achalasia: an in vitro study. Gut 1990;30:762-7.

44 Holloway RH, Kocyan P, Dent J. Provocation of transient lower esophageal sphincter relaxations by meals in patients with symptomatic gastroesophageal reflux. Dig Dis Sci 1991;36:1034-9.

45 Nebel OT, Castell DO. Lower esophageal sphincter pressure changes after food ingestion. Gastroenterology 1972;63:77883.

46 Lu C, Schulze-Delrieu K, Shirazi S, et al. Dynamic imaging of obstructed opossum esophagus. Dig Dis Sci 1994;39: $1377-88$ 